\title{
Bullefin
}

ISSN 0003-0007

\section{of the American}

Meteorological

Socielly

\section{Volume 59 Number 12 December 1978}

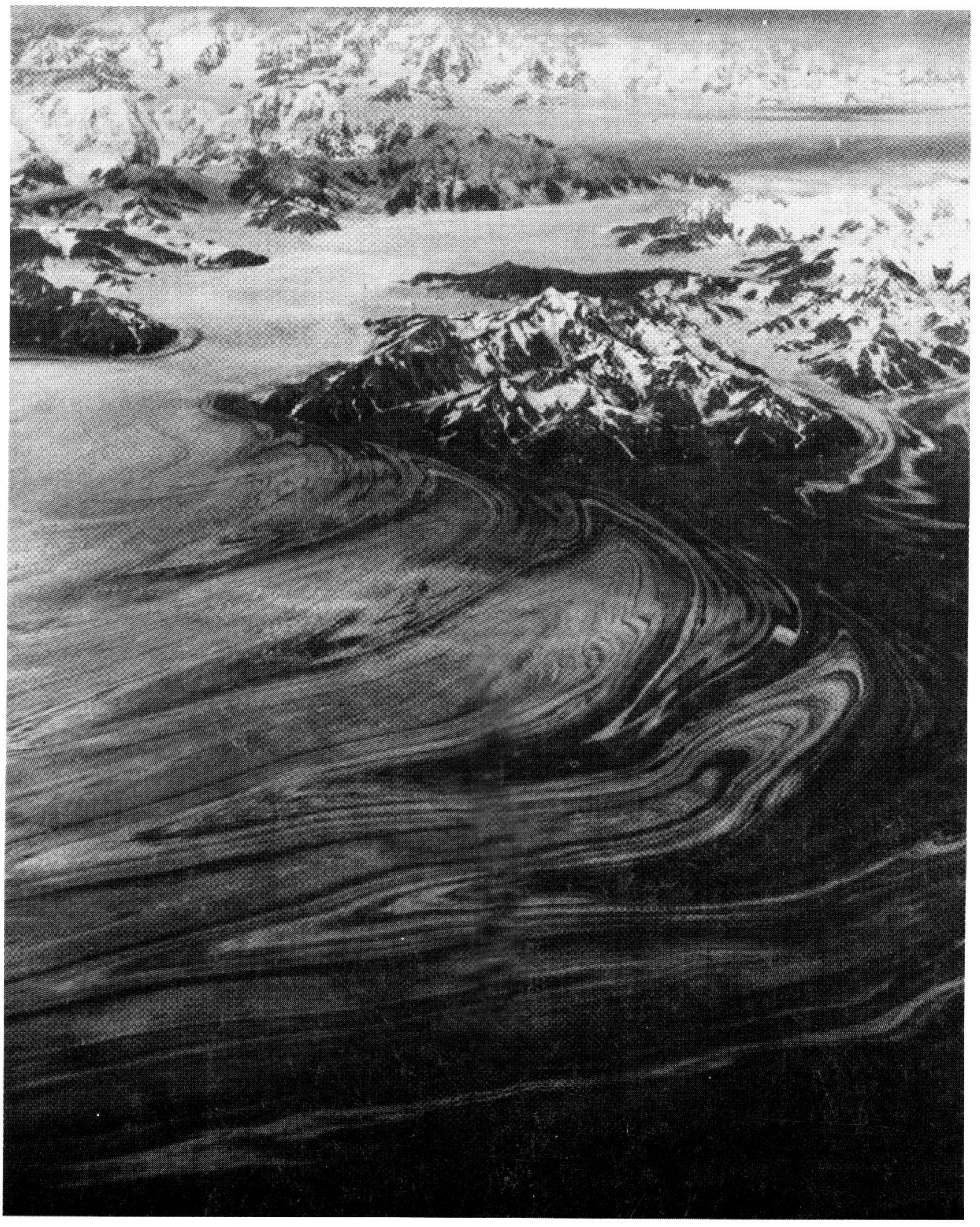




\section{ARE YOU ENERGY-ORIENTED?}

If you're looking for answers-in the wind, sun, or water-we can help you select instruments that will meet your technical specifications and your budget.

Write for our revised literature. Many sections-all part of Catg. No. 9-have been completed.

Temperature Humidity Atmospheric Pressure

Wind

Precipitation, Hydrology

Solar Radiation Sec. 6 Rev. D Upper Air \& Visibility

Towers \& Masts Sec. 8

More sections are in preparation.

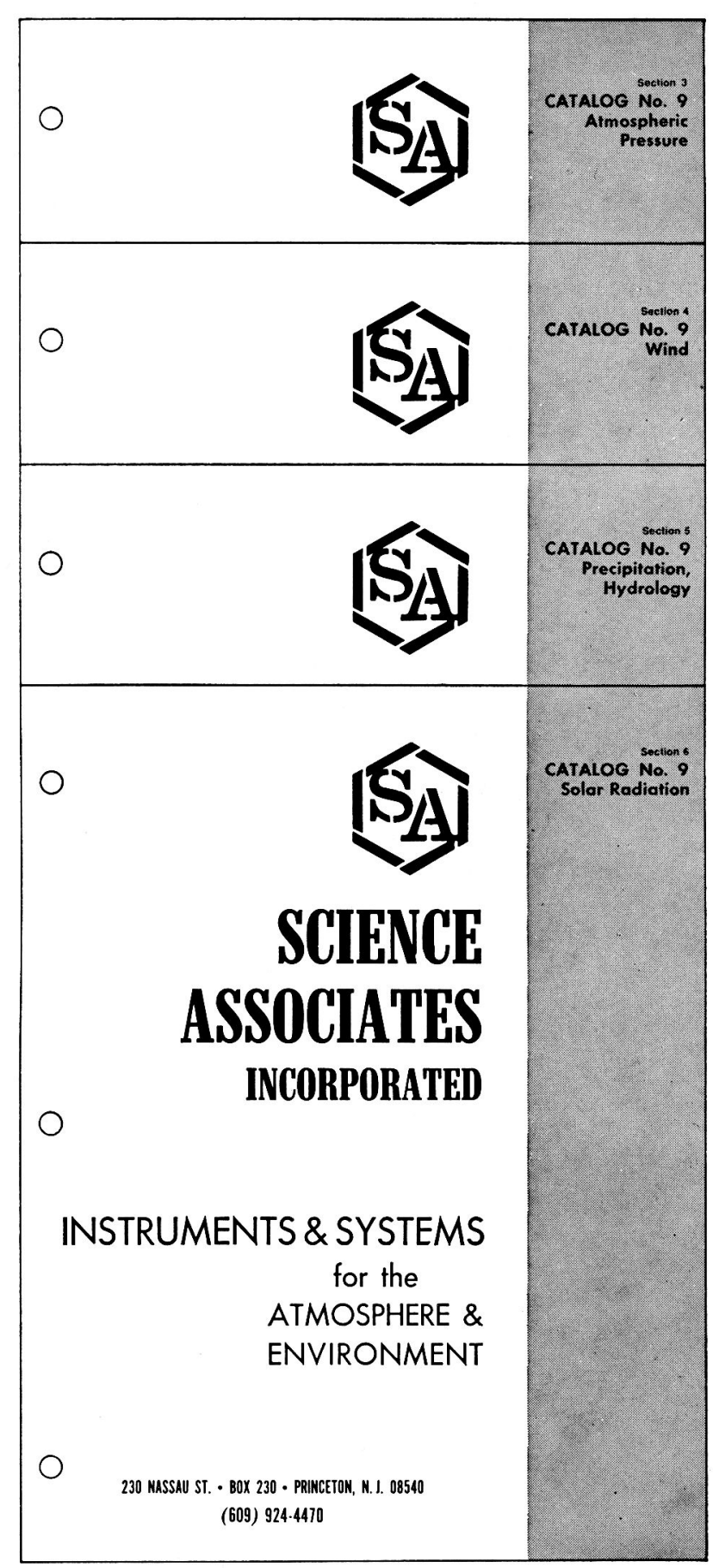




\section{AUTOMATIC WORLDWIDE RECEPTION OF WEATHER SATELLITE FACSIMILE TRANSMISSIONS}

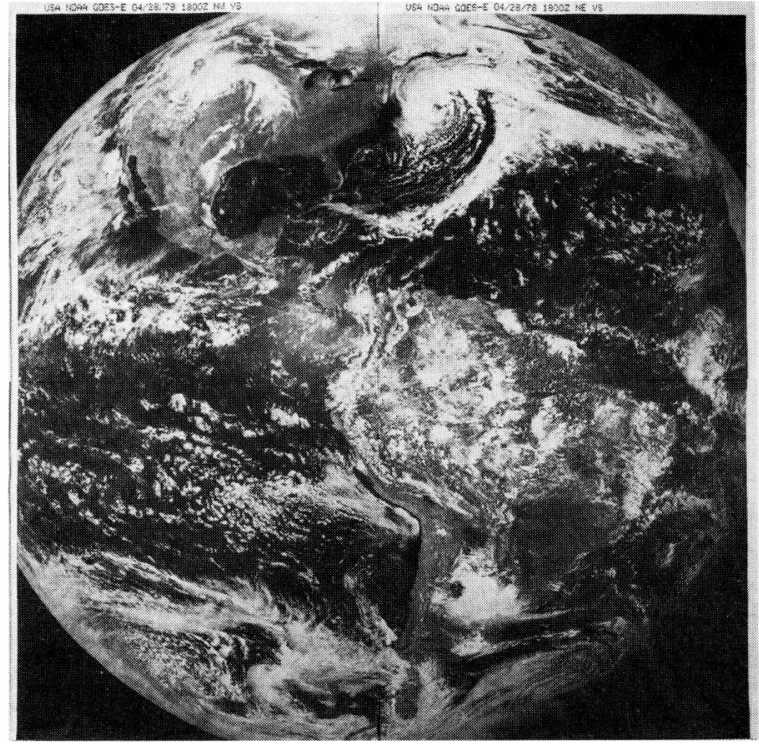

Four quadrant mosaic from GOES-E showing South America, adjacent waters, the Caribbean, Central and North America. A storm is shown of the east coast of the United States and Canada. Recorded on the ALDEN 1100 APTS/Weather Chart Recorder, Model 9273R, as used in the APTS-3B Satellite Ground Receiving Station with WEFAX option.

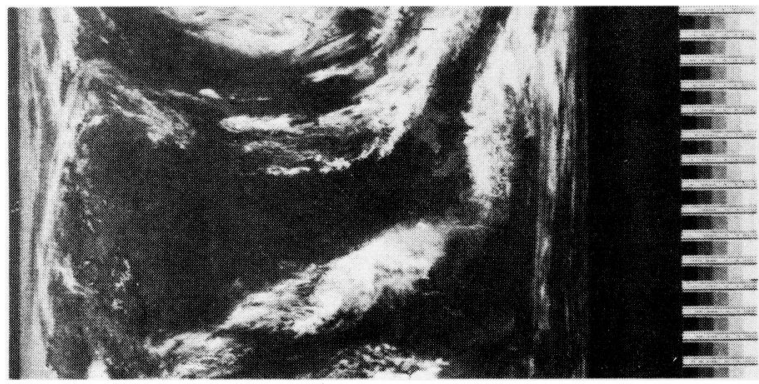

VIS transmission from NOAA recorded on ALFAX Recording Paper Single, expanded VIS recorded off tape at 96 scans/minute.

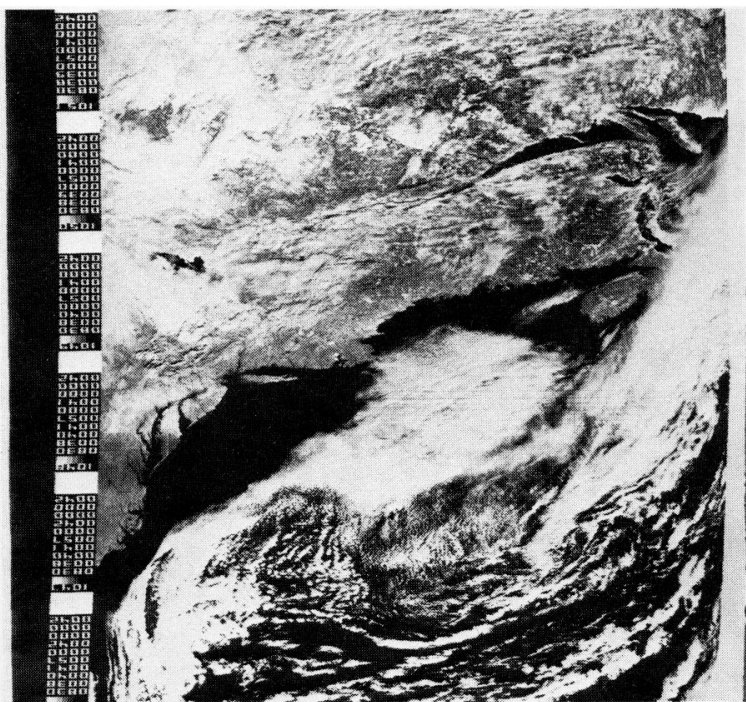

Tape playback of picture received on the ALDEN APTS-3C Orbiting Satellite Ground Receiving Station from the Russian Satellite, NATUR. Clearly visible are cloud formations over the Atlantic Ocean with the St Lawrence Seaway and east coast of the United States also shown. Picture was recorded on the ALDEN 1800 AVD Universal Weather Graphic Recorder and is expanded to an 18 in. width

\section{with ALDEN Satellite Ground Receiving Systems}

ALDEN offers three satellite ground receiving systems designed to receive sharply detailed pictures from orbiting satellites such as NOAA and TIROS-N and synchronous meteorological satellites (WEFAX MODE) GOES-E, GOES-W, METEOSAT and GMS (LR-FAX).

Each system is dedicated to its weather satellite mission and includes all necessary antennas, preamplifiers, telemetry receivers, facsimile recorders and system consoles . . . all human engineered for easy installation, operation and maintenance.

ALDEN APTS-3B SATELLITE GROUND RECEIVING STATION The ALDEN APTS-3B Satellite Ground Receiving Station, the universal system, is designed to receive satellite pictures and weather charts from:

- Orbiting weather satellites

- Synchronous meteorological satellites

- HF radiofacsimile broadcasts

- Landline facsimile networks

This station incorporates an omni-directional antenna which eliminates satellite tracking and permits unattended operation. The operator need only select the frequency for the desired satellite; when the signal is present, the ALDEN APTS Recorder and tape recorder automatically start and record the satellite data.

The APTS-3B System is designed on the building block principle. Equipped with the WEFAX parabolic antenna option, it automatically receives WEFAX transmissions from the synchronous meteorological satellites.

The HF radiofacsimile option features a fully synthesized HF receiver which permits reception of any HF radiofacsimile weather broadcast.

ALDEN Recorders use Alfax Electrosensitive Recording Paper which has unlimited storage life, unequalled performance under all environmental conditions, a broad range of tone shades and provides rich, sepia-colored pictures of archival quality.

\section{ALDEN 1100 WEFAX GROUND RECEIVING SYSTEM}

The ALDEN 1100 WEFAX Ground Receiving System is a dedicated system for the reception of WEFAX transmissions from GOES, METEOSAT and GMS (LR-FAX) synchronous meteorological satellites. Simple and reliable, the system permits unattended operation and provides continuous, clearly detailed 101/2-inch square satellite pictures.

\section{ALDEN APTS-3C ORBITING WEATHER SATELLITE GROUND RECEIVING STATION}

The ALDEN APTS-3C Satellite Ground Receiving Station is a dedicated system for automatic reception of all VHF transmissions from orbiting weather satellites through the use of an omni-directional antenna which eliminates satellite tracking and permits unattended operation. The signal inputs are digitally processed and expanded to large, detailed pictures 18 inches wide, utilizing the ALDEN 1800 A/D Universal Weather Graphic Recorder, Model 9500S. This recorder offers the unique capability of recording IR and VIS side-byside with each channel having a 9 in. width, or fully expanded IR or VIS to 18 in. width.

Use the coupon today for details

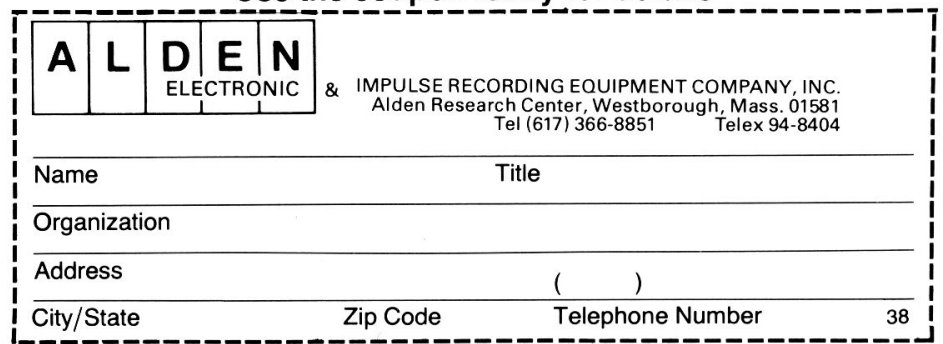




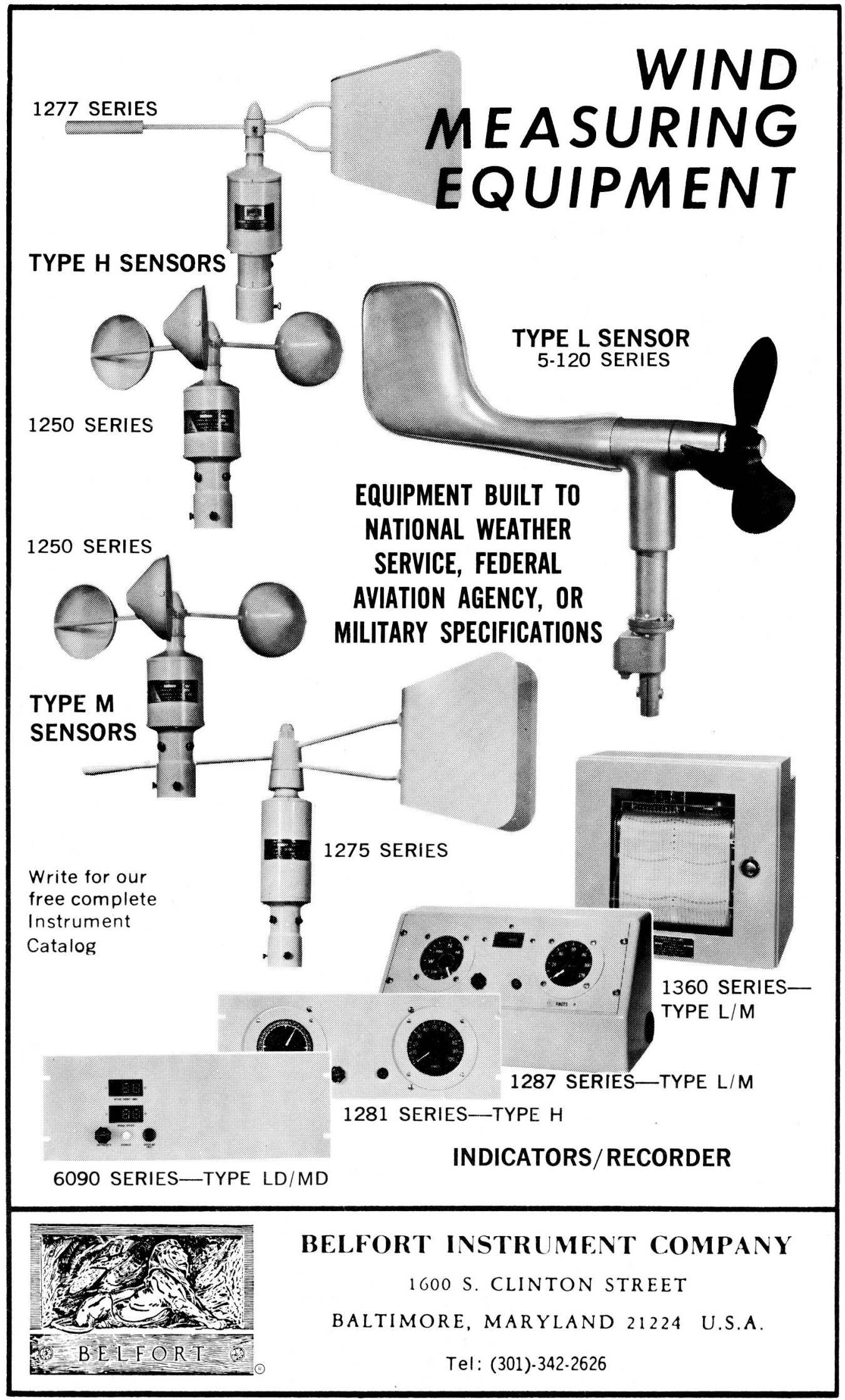


Bulletiln

of the American

Meleorological

Socielly

Editor, Kenneth C. Spengler

Technical Editor, J. E. Caskey, Jr.

Educational Affairs Editor,

Owen E. Thompson

Focus on Forecasting Editor,

Frederick Sanders

News Editor, Eileen M. Blum

Copy Editor, Joan Urdang

Meetings Editor, Evelyn Mazur

Assistant Meetings Editor,

Twila A. Bombard

Advertising, Lilly G. Albo

The Bulletin of the American MeteoroLOGICAL Society is the official organ of the Society, devoted to editorials, survey articles, professional and membership news, announcements, and Society activities. Editing and publishing are under the direction of Kenneth C. Spengler, Executive Director. Members are encouraged to send information to be considered for publication. Send four copies of each manuscript (text and illustrations). For guidance on preparation and style, see "Information for Contributors" on inside covers of a recent AMS research journal.

AMS Officers and Councilors: President, George P. Cressman; President-Elect, Chester W. Newton; Executive Director, Kenneth C. Spengler; Secretary-Treasurer, David F. Landrigan; Past Presidents, Charles L. Hosler, Jr., and Werner A. Baum; and Councilors: Bernice Ackerman, William D. Bonner, James P. Bruce, Francis S. Johnson, Albert J. Kaehn, Jr., Roy L. Leep, Jr., Margaret A. LeMone, Frederick P. Ostby, Jr., Norman A. Phillips, Frederick Sanders, Robert W. Stewart, Verner E. Suomi, John E. Wallace, Robert M. White, Jay S. Winston.

Published monthly by the American Meteorological Society at 45 Beacon St., Boston, Mass. 02108. Second-class postage paid at Boston, Mass., and at additional mailing offices. Subscription price to members is included in annual dues ( $\$ 20$ per year). Subscription price to nonmembers is available on request; single issues are $\$ 10$ each. Address all business communications, purchase orders, and inquiries to the Executive Director, American Meteorological Society, 45 Beacon St., Boston, Mass. 02108 (617-227-2425).
Volume 59, Number 12, December 1978

articles

Earth-Atmosphere Radiative Heating Based on NOAA Scanning Radiometer Measurements . . . . . . . . . A. Gruber and J. S. Winston

The Improved NWS Storm Spotters' Training Program at Ft. Worth, Tex. . . . . . . . . . . . . . . . . . . . . A. R. Moller

NWS Hazardous Weather Terminology . . . . B. Pifer and H. M. Mogil

A Chronology of Important Events in the History of Air Pollution Meteorology to $1970 \ldots \ldots \ldots$. . . . . . . . . . . . K. C. Heidorn

focus on forecasting

Evaluation of a 5 -Year Forecast . . . . . . . . . . J. Vederman

1598

GARP Topics

Role of Observational Errors in Optimum Interpolation Analysis K. H. Bergman

1603

correspondence

Observations of the Malaspina Glacier E. M. Agee

1612

Information Content of Satellite Images

D. D. Houghton and V. E. Suomi

1614

public policy affairs

NASA's Role in Weather Prediction . . . . . . . . . . . I. Rasool 1618

meeting review

18th Conference on Radar Meteorology

R. G. Humphries and J. I. Metcalf

1625

program

Ninth Conference on Weathercasting (Radio and TV) of the American Meteorological Society announcements

1582

book reviews

1628

minutes of the council ..... 1634

STAC frame of reference . . . 1638

about our members . . . . . . . 1644

news from our chapters . . . . . 1648

corrigendum .......... 1650

at $\mathrm{AMS}$ headquarters

1651 news and notes ......... 1640
AMS announces undergraduate awards and scholarships ... 1652 AMS notices ........... 1653 calendar of meetings ....... 1654 contents of AMS journals .... 1670 corporation members ........ 1674 professional directory ...... 1675 index to $1978 \ldots \ldots \ldots \ldots . . .685$ index to advertisers ....... 1704
Cover photograph. A dramatic display of compressional waves in the piedmont lobe of the Malaspina glacier over southeast Alaska. Photo was taken from commercial aircraft on 23 September 1975 by Ernest M. Agee. For more photos and details, see correspondence by Agee, which begins on page 1612 .

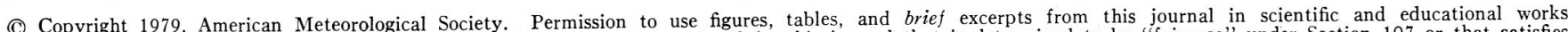

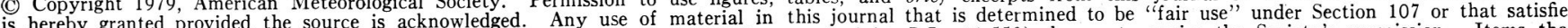

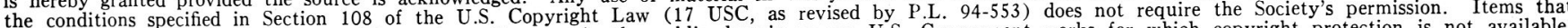

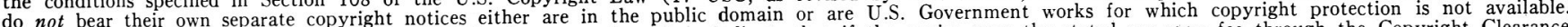

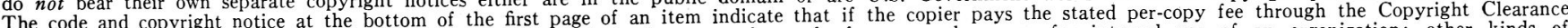

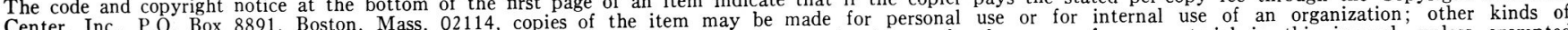

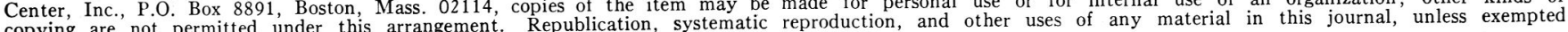
by the above statements, require permission or license from the American Meteorological Society. 